\title{
Randomized, placebo-controlled, double-blind clinical trial to evaluate the efficacy of polyhexanide for topical decolonization of methicillin-resistant Staphylococcus aureus (MRSA) carriers
}

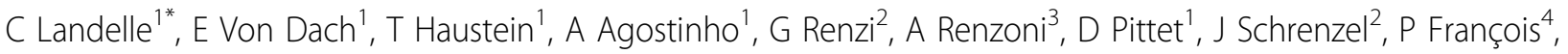 \\ S Harbarth ${ }^{1}$
}

From 3rd International Conference on Prevention and Infection Control (ICPIC 2015)

Geneva, Switzerland. 16-19 June 2015

\section{Introduction}

Due to increasing resistance, alternatives to mupirocin and chlorhexidine for decolonization of MRSA carriage need to be evaluated.

\section{Objectives}

To evaluate the efficacy of polyhexanide (Prontoderm ${ }^{\circledR}$ ) $v s$ placebo in eliminating MRSA carriage at day 28 (D28) after the end of treatment.

\section{Methods}

In a 1,900-bed teaching hospital, MRSA-colonized patients were randomized into a double-blind, placebocontrolled superiority trial. Patients were treated with either polyhexanide (antiseptic and surface-active substances; group I) or placebo (only surface-active substances; group P) applied to the anterior nares and skin for 10 days. The primary outcome was MRSA decolonization at D28 assessed by both intention-to-treat ([ITT] responder analysis) and per-protocol (PP) analysis (microbiological follow-up \pm 7 days and topical treatment $\geq 5$ days). Secondary outcomes included MRSA decolonization according to nasal MRSA carriage, safety and emergence of resistance.

'Infection Control Program, University Hospitals of Geneva and Faculty of Medicine, Geneva, Switzerland

Full list of author information is available at the end of the article

\section{Results}

Of 2590 patients screened, 146 patients (group I, 71; group P, 75) were randomized between January 2011 and July 2014. Primary outcome was missing for 11 (7.5\%) patients. ITT analysis showed that $24 / 71$ (33.8\%) patients in group I vs 22/75 (29.3\%) in group P were MRSA-free at D28 (risk difference, 4.5\%; 95\% CI, $-10.6 \%$ to $19.5 \% ; P=0.56)$. PP analysis confirmed the results with 19/53 (35.8\%) decolonized polyhexanide-treated patients vs 17/56 (30.4\%) in the placebo arm (risk difference, $5.5 \%$; $95 \% \mathrm{CI},-12.2 \%$ to $23.0 \% ; P=0.54)$. In the subgroup of MRSA nasal carriers, PP analysis showed that $6 / 15(40.0 \%)$ patients in group I $v s 2 / 11(18.2 \%)$ in group $\mathrm{P}$ were decolonized $(P=0.40)$. Nine serious adverse events occurred in group I vs 12 in group P; none was attributable to study medication. Emergence of polyhexanide resistance was not observed.

\section{Conclusion}

This study suggests that under real-life conditions a single polyhexanide decolonization course is marginally effective in eradicating MRSA carriage.

\section{Disclosure of interest}

C. Landelle: None declared, E. Von Dach: None declared, T. Haustein: None declared, A. Agostinho: None declared, G. Renzi: None declared, A. Renzoni: None declared, D. Pittet: None declared, J. Schrenzel: None declared, P. François: None declared, S. Harbarth 
Grant/Research support from: a peer-reviewed research grant funded by Pfizer, Consultant for: the advisory boards of Destiny Pharma, bioMerieux, Novartis, and DaVolterra

\section{Authors' details}

'Infection Control Program, University Hospitals of Geneva and Faculty of Medicine, Geneva, Switzerland. ${ }^{2}$ Clinical Microbiology Laboratory, University Hospitals of Geneva and Faculty of Medicine, Geneva, Switzerland. ${ }^{3}$ Service of Infectious Diseases, University Hospitals of Geneva and Faculty of Medicine, Geneva, Switzerland. ${ }^{4}$ Genomic Research Laboratory, University Hospitals of Geneva and Faculty of Medicine, Geneva, Switzerland.

Published: 16 June 2015

doi:10.1186/2047-2994-4-S1-06

Cite this article as: Landelle et al: Randomized, placebo-controlled, double-blind clinical trial to evaluate the efficacy of polyhexanide for topical decolonization of methicillin-resistant Staphylococcus aureus (MRSA) carriers. Antimicrobial Resistance and Infection Control 2015 4(Suppl 1):O6.

Submit your next manuscript to BioMed Central and take full advantage of:

- Convenient online submission

- Thorough peer review

- No space constraints or color figure charges

- Immediate publication on acceptance

- Inclusion in PubMed, CAS, Scopus and Google Scholar

- Research which is freely available for redistribution

Submit your manuscript at www.biomedcentral.com/submit
C Biomed Central 